\title{
Nanorod Aspect Ratios Determined by the Nano-Impact Technique
}

\author{
Blake J. Plowman, Neil P. Young, Christopher Batchelor-McAuley and Richard G. Compton*
}

\begin{abstract}
We report the in situ electrochemical sizing of individual gold nanorods. Through the combination of electrochemical dissolution and the use of a surface-bound redox tag the volume and surface area of the nanorods are measured, and provide the aspect ratio and the size of the nanorods. Excellent independent agreement is found with electron microscopy analysis of the nanorods, establishing the application of nanoimpact experiments for the sizing of anisotropic nanomaterials.
\end{abstract}

As the exploration of the synthesis, characterization and properties of nanomaterials advances, an important and widely recognized relationship exists between the size and shape of the nanomaterials and their behavior.. ${ }^{[1]}$ This has led to an ever increasing search for methods to fabricate precisely controlled multidimensional nanostructures, with geometries such as spheres, cubes, triangles and rods, to name a few, driven by the desire to alter the optical, catalytic and sensing properties of the materials. ${ }^{[2]}$ In the case of gold nanorods the aspect ratio of the materials is closely linked with their properties, ${ }^{[2 b, 3]}$ necessitating careful characterization in order to rationalize their behavior.

The determination of nanorod aspect ratios has been accomplished by methods such as transmission electron microscopy (TEM) and atomic force microscopy, ${ }^{[4]}$ however the characterisation time and limited sample sizes can hinder these techniques. An alternative technique is based on UV-visible spectroscopy, where the position of the longitudinal surface plasmon resonance (SPR) peak is used to measure the aspect ratio of the gold nanorods. ${ }^{[5]}$ However it has been noted that this technique can involve several limitations such as the sensitivity of the optical properties of the nanorods to the local dielectric field and the geometry of the nanorods, ${ }^{[6]}$ as well as requiring materials which display SPR peaks in the UV-visible range.

An attractive alternative to these methods is through the use of an electrochemical approach at the single nanorod level. This method has been pioneered for spherical nanoparticles through nanoimpact experiments, where the electrochemical size determination of the materials has been established and verified alongside other methods. This approach relies upon the impact of individual nanoparticles with an electrode surface, ${ }^{[7]}$ where control of the applied potential leads to either the direct ${ }^{[8]}$ or indirect ${ }^{[8 \mathrm{c}, 9]}$ observation of the nanoparticles via their electrodissolution. While this method has shown remarkable success for the sizing of spherical or quasi-spherical nanoparticles, its extension to determine the dimensions of non-spherical

[*] Dr. Blake J. Plowman, Dr. Christopher Batchelor-McAuley and Prof. Richard G. Compton

Department of Chemistry, PTCL

University of Oxford, South Parks Road

Oxford, OX13QZ (UK)

E-mail: richard.compton@chem.ox.ac.uk

Dr. Neil P. Young

Department of Materials,

University of Oxford, Parks Road

Oxford, OX13PH (UK) geometries is unexplored, marking an exciting opportunity for growth in this field. In this work we therefore investigate the novel application of nanoimpacts for the characterisation of gold nanorods, which serves as a model system to probe the determination of both the size and shape of the impacting nanomaterials.

The dimensions of the citrate-capped gold nanorods were first examined by TEM, as seen in Figure 1a. A total of 222 nanorods were measured, showing an average length of $74 \pm 7$ $\mathrm{nm}$ and diameter of $21 \pm 1 \mathrm{~nm}$ (Figure 1b). The average aspect ratio $(p)$, given as the ratio of the length $(I)$ to the diameter $(d)$ of the nanorods was then calculated using Eq. 1, giving a value of $3.5 \pm 0.4$.

$$
p=\frac{l}{d}
$$
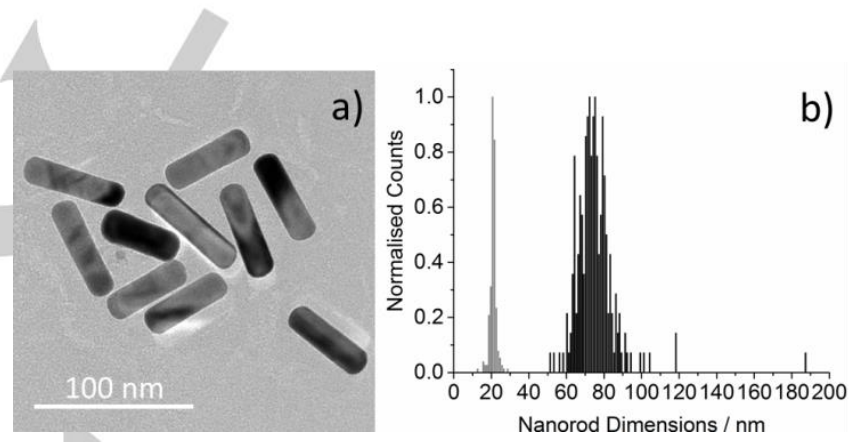

Figure 1. a) Bright field TEM image of gold nanorods, with the measured nanorod diameters (gray) and lengths (black) in b).

Prior to performing impacts experiments, the stability of the nanorods in different electrolytes was probed by UV-visible spectroscopy. In the presence of water alone (Figure 2a, red curve) the response is found to be stable, however in the presence of $\mathrm{HCl}$ (Figure 2a) the peak magnitudes can be seen to decrease with peak broadening to the near-infrared region. These features indicate that substantial agglomeration takes place under these conditions ${ }^{[10]}$ and is therefore not desirable for nanoimpact experiments. Similar studies were conducted in the presence of $\mathrm{KCl}$ (Figure $2 \mathrm{~b}$ ), where a negligible decrease in the peak magnitude occurs for concentrations of up to $40 \mathrm{mM} \mathrm{KCl}$, while in $100 \mathrm{mM} \mathrm{KCl}$ (blue curve) a gradual peak decrease accompanied by an increased absorption in the near infrared region takes place. Comparison of Figures $2 \mathrm{a}$ and $2 \mathrm{~b}$ reveals that the substantial agglomeration observed in the former case is likely driven by the protonation of the citrate capping agent, ${ }^{[11]}$ while in the latter case the agglomeration is attributed to the screening of the nanoparticle charge by the increased ionic strength. ${ }^{[12]}$ Nevertheless a low ionic strength $\mathrm{KCl}$ system provides an excellent framework to investigate the electrochemical properties of individual gold nanorods. 

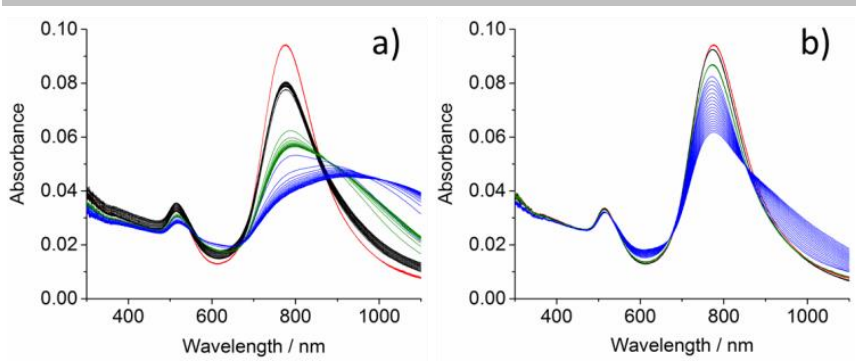

Figure 2. UV-visible spectroscopy of $100 \mathrm{pM}$ gold nanorods suspended in 0 $\mathrm{mM}$ (red), $20 \mathrm{mM}$ (black), $40 \mathrm{mM}$ (green) or $100 \mathrm{mM}$ (blue) $\mathrm{HCl}$ (a) or $\mathrm{KCl}$ (b).

Having established the stability of the nanorods in $\mathrm{KCl}$, cyclic voltammetry $(\mathrm{CV})$ of the nanorods was then performed in $40 \mathrm{mM}$ $\mathrm{KCl}$. As seen in Figure $3 \mathrm{a}$, the oxidative dissolution of a gold nanorod modified glassy carbon surface occurs at ca. $1.01 \mathrm{~V}$ vs SCE, with the oxidative charge decreasing rapidly with consecutive scans. This is in agreement with prior work on the dissolution of gold nanoparticles in $\mathrm{HCl}$, where the reaction was found to proceed through the formation of both $\mathrm{Au}^{+}$and $\mathrm{Au}^{3+}$ species (Eqs. (2) and (3)), with the overall reaction occurring as a near two electron oxidation per gold atom. ${ }^{[13]}$

$$
\begin{aligned}
& \mathrm{Au}+2 \mathrm{Cl}^{-} \rightleftarrows \mathrm{AuCl}_{2}{ }^{-}+e^{-} \\
& \mathrm{Au}+4 \mathrm{Cl}^{-} \rightleftarrows \mathrm{AuCl}_{4}{ }^{-}+3 e^{-}
\end{aligned}
$$

The impact of nanorods was then performed in $\mathrm{KCl}$ to determine the volume of individual nanorods. To accomplish this chronoamperograms (CA) were recorded in a $10 \mathrm{pM}$ suspension of gold nanorods in $40 \mathrm{mM} \mathrm{KCl}$ using a carbon fibre microcylinder electrode ${ }^{[14]}$ with an applied potential of $1.3 \mathrm{~V}$ vs SCE. As is demonstrated in Figure $3 b$, oxidative spikes were seen, evidencing the oxidative dissolution of individual nanorods. No spikes were observed in the absence of the nanorods (Figure S1), or at a potential of $0.7 \mathrm{~V}$ vs SCE in the presence of the nanorods (Figure S2). A total of 301 impacts were integrated (Figure 3c), and the average charge was found to be $4.0( \pm 1.2) \times 10^{-13} \mathrm{C}$. Note that the standard deviation is given here, representing both the error of the measurement as well as the size dispersion of the nanorods. Interestingly the presence of nanorod dimers can also be observed in Figure $3 \mathrm{c}$, with the peak positions, standard deviations and relative ratio between the monomers and dimers showing excellent agreement with previous work on the entropy of mixing driven agglomeration of nanoparticles. ${ }^{[15]}$

The average volume of the nanorods was then calculated using Eq. 4:

$$
V=\frac{Q A_{W}}{Z D F}
$$

where $V$ is the volume $\left(\mathrm{m}^{3}\right), Q$ is the oxidative charge $(C), A w$ is the atomic weight of gold $\left(196.97 \mathrm{~g} \mathrm{~mole}^{-1}\right), Z$ is the number of electrons transferred (1.9 electrons per gold atom, as determined previously $\left.{ }^{[13]}\right), D$ is the density of gold $\left(\mathrm{g} \mathrm{m}^{-3}\right)$ and $F$ is the Faraday constant $\left(96,485 \mathrm{C} \mathrm{mole}^{-1}\right)$. From Eq. 4 it is found that the average nanorod volume determined by nanoimpacts is $2.2( \pm 0.7) \times 10^{4} \mathrm{~nm}^{3}$. This value was then compared with the expected nanorod volume based on the TEM measurements, assuming a hemispherical end cap, according to Eq. 5:

$$
V=\pi r^{2} l-\frac{2}{3} \pi r^{3}
$$

where $l$ is the length $(m)$ and $r$ is the radius $(m)$. This gave a value of $2.3( \pm 0.4) \times 10^{4} \mathrm{~nm}^{3}$, showing a difference of less than
$3 \%$ from the volume obtained through the electrochemical approach and establishing the use of nanoimpacts to determine the volume of the nanorods.
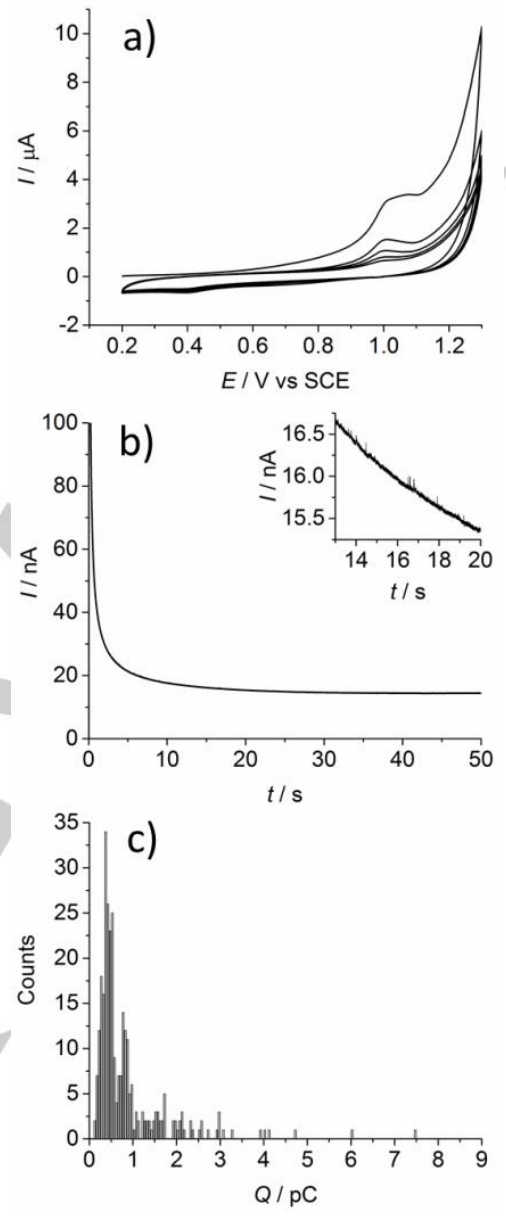

Figure 3. a) $\mathrm{CVs}$ in $40 \mathrm{mM} \mathrm{KCl}$ at $25 \mathrm{mV} \mathrm{s}^{-1}$ for a glassy carbon electrode drop cast with $4 \mu \mathrm{L}$ of gold nanorods, showing the first five scans. b) CA obtained at $1.3 \mathrm{~V}$ vs SCE for a carbon microcylinder electrode in a $10 \mathrm{pM}$ suspension of gold nanorods in $40 \mathrm{mM} \mathrm{KCl}$. c) The distribution of impact charges.

While for spherical nanoparticles the identification of the volume is sufficient to size the particles, for the present case this does not apply as the same volume may be found for nanorods with markedly different aspect ratios. In order to overcome this challenge the surface areas of the nanorods were next analysed by tagging the nanorods with 4-nitrothiophenol (NTP), which has been demonstrated to undergo a four electron reduction and allow the quantification of the surface area of nanoparticles. ${ }^{[16]}$ The modification of the nanorod capping agent was then tested by $\mathrm{CV}$ in $10 \mathrm{mM} \mathrm{HClO}_{4} 30 \mathrm{mM} \mathrm{NaClO}_{4}$, and from Figure 4a the reduction of the NTP-modified nanorods can be readily observed (black curve).

Nanoimpact experiments were then performed using the NTP-modified nanorods with an applied potential of $-0.35 \mathrm{~V}$ vs SCE. As can be seen from Figure $4 \mathrm{~b}$ this resulted in the presence of reductive spikes, while impacts were not observed at $-0.1 \mathrm{~V}$ (Figure S2) or at a potential of $-0.35 \mathrm{~V}$ in the absence of the nanorods (Figure S3). The impact charges are shown in Figure 4c, with a modal charge of $1.2( \pm 0.5) \times 10^{-14} \mathrm{C}$. It should be noted that the presence of nanorod dimers (as seen in Figure 3c) are not apparent in this case, which may be attributed to the altered nanorod stability in the presence of the different 
electrolytes and capping agents. The surface area of the nanorods was then calculated using Eq. 6:

$$
A_{N R}=\frac{A_{N T P} N_{A} Q}{Z F}
$$

where $A_{N R}$ is the surface area of the nanorod $\left(\mathrm{m}^{2}\right), A_{N T P}$ is the area per molecule of NTP $\left(2.6 \times 10^{-9} \mathrm{~m}^{2}\right.$ per molecule), ${ }^{[17]} N_{A}$ is the Avogadro constant, $Q$ is the reductive charge $(C), Z$ is the number of electrons transferred (4) and $F$ is the Faraday constant. From Eq. 6 the average surface area of the nanorods was determined to be $4.6( \pm 1.9) \times 10^{3} \mathrm{~nm}^{2}$. This value was then compared with the expected surface area of the nanorods using Eq. 7 with the average nanorod length and radius from the TEM analysis. This gave a surface area of $4.9( \pm 0.7) \times 10^{3} \mathrm{~nm}^{2}$, which is within $5 \%$ of that determined by the nanoimpacts method.

$A=2 \pi r l$
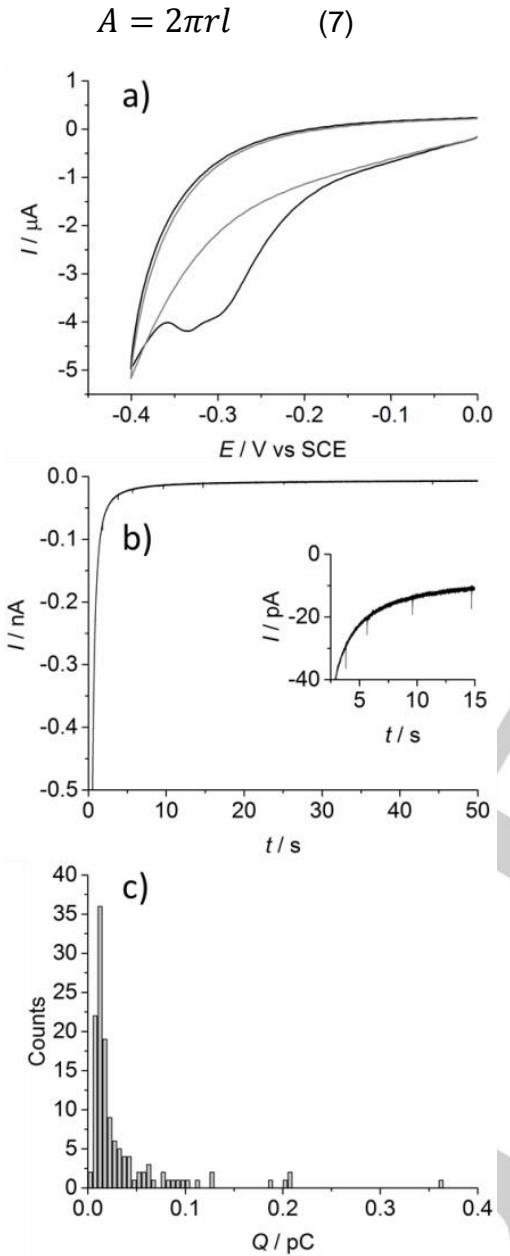

Figure 4. $\mathrm{CVs}$ in $10 \mathrm{mM} \mathrm{HClO}_{4}, 30 \mathrm{mM} \mathrm{NaClO}_{4}$ at $25 \mathrm{mV} \mathrm{s}^{-1}$ for a glassy carbon electrode drop cast with (black) or without (gray) $4 \mu \mathrm{L}$ of NTP-modified nanorods. b) CA obtained at $-0.35 \mathrm{~V}$ vs SCE for a carbon microdisk electrode in a suspension of $10 \mathrm{pM}$ NTP-modified nanorods in $10 \mathrm{mM} \mathrm{HClO}_{4}, 30 \mathrm{mM}$ $\mathrm{HClO}_{4}$. c) The distribution of impact charges.

In addition to providing accurate measurements of the surface areas and volumes of the nanorods, the results can also reveal the dimensions of the impacting nanorods. In the case of an unknown sample, the sphericity of the nanomaterials may firstly be determined by the isoperimetric quotient, helping to distinguish the overall structure of the nanoparticles. ${ }^{[18]}$ As is shown in the Supporting Information, for a hemispherically capped nanorod where $1>2 r$, the radius of the nanorods can be calculated using Eq. 8:

$$
\frac{4}{3} \pi r^{3}-A r+2 V=0
$$

Using the electrochemically determined nanorod volume and surface area, the average nanorod diameter is $21 \pm 11 \mathrm{~nm}$, and from Eq. 7 the average length is $67 \pm 7 \mathrm{~nm}$. The electrochemically determined aspect ratio (Eq. 1) is therefore found to be $3.1 \pm 1.7$. These values are in excellent agreement with the TEM analysis $(21 \pm 1 \mathrm{~nm}$ diameter, $74 \pm 7 \mathrm{~nm}$ length, aspect ratio of $3.5 \pm 0.4$ ), highlighting the power of this method to determine the dimensions of non-spherical nanomaterials on an individual basis.

In this work we have successfully demonstrated the complete size characterisation of non-spherical nanomaterials using individual nanorods. This proof of concept has been established in the case of gold nanorods by analysing their volume and surface area at the single nanorod level through separate experiments, with the latter measurement performed by changing the nanorod capping agent. This is the first time that nanoimpacts have been utilised to determine the shape and size of the impacting nanoparticles, opening up this technique to the characterisation of a wide range of nanomaterials with nonspherical geometries.

\section{Acknowledgements}

The authors gratefully acknowledge the support of a Marie Curie International Incoming Fellowship (B.J.P., project number 630069).

Keywords: aspect ratio $\cdot$ characterisation $\cdot$ electrochemistry • nanoimpacts $\cdot$ nanorods

[1] a) L. Shi, C. Jing, W. Ma, D.-W. Li, J. E. Halls, F. Marken, Y.-T. Long Angew. Chem. 2013, 125, 6127-6130; b) M.-C. Daniel, D. Astruc Chem. Rev. 2004, 104, 293-346; c) A. Chen, S. Chatterjee, Chem. Soc. Rev. 2013, 42, 5425-5438; d) J. Zhang, A. M. Kuznetsov, I. G. Medvedev, Q. Chi, T. Albrecht, P. S. Jensen, J. Ulstrup, Chem. Rev. 2008, 108, 2737-2791.

[2] a) T. K. Sau, A. L. Rogach, F. Jäckel, T. A. Klar, J. Feldmann, Adv Mater. 2010, 22, 1805-1825; b) P. Kannan, S. Sampath, S. A. John, J. Phys. Chem. C 2010, 114, 21114-21122.

[3] a) J. S. Sekhon, S. Verma, Plasmonics 2011, 6, 163-169; b) S. E. Lohse, C. J. Murphy, Chem. Mater. 2013, 25, 1250-1261.

[4] a) J. Pérez-Juste, I. Pastoriza-Santos, L. M. Liz-Marzán, P. Mulvaney, Coord. Chem. Rev. 2005, 249, 1870-1901; b) S. Hsieh, S. Meltzer, C. R. C. Wang, A. A. G. Requicha, M. E. Thompson, B. E. Koel, J. Phys. Chem. B 2002, 106, 231-234

[5] a) A. S. Stender, G. Wang, W. Sun, N. Fang, ACS Nano 2010, 4, 7667 7675; b) S. Link, M. Mohamed, M. El-Sayed, J. Phys. Chem. B 1999 103, 3073-3077.

[6] a) A. Gulati, H. Liao, J. H. Hafner, J. Phys. Chem. B 2006, 110, 22323 22327; b) C. Pecharromán, J. Pérez-Juste, G. Mata-Osoro, L. M. Liz Marzán, P. Mulvaney, Phys. Rev. B 2008, 77, 035418

[7] a) W. Cheng, R. G. Compton, TRAC Trends Anal. Chem. 2014, 58, 79 89; b) M. Pumera, ACS Nano 2014, 8, 7555-7558; c) N. V. Rees Electrochem. Commun. 2014, 43, 83-86.

[8] a) Y.-G. Zhou, N. V. Rees, R. G. Compton, Angew. Chem. Int. Ed. 2011 50, 4219-4221; b) C. S. Lim, M. Pumera, Phys. Chem. Chem. Phys 2015, 17, 26997-27000; c) C. S. Lim, S. M. Tan, Z. Sofer, M. Pumera ACS Nano 2015, 9, 8474-8483; d) V. Brasiliense, A. N. Patel, A 
Martinez-Marrades, J. Shi, Y. Chen, C. Combellas, G. Tessier, F. Kanoufi, J. Am. Chem. Soc. 2016, 138, 3478-3483.

[9] a) X. Li, C. Batchelor-McAuley, S. A. I. Whitby, K. Tschulik, L. Shao, R. G. Compton, Angew. Chem. Int. Ed. 2016, 55, 4296-4299; b) X. Xiao, A. J. Bard, J. Am. Chem. Soc. 2007, 129, 9610-9612.

[10] a) Y. Wang, A. E. DePrince III, S. K. Gray, X.-M. Lin, M. Pelton, J. Phys Chem. Lett. 2010, 1, 2692-2698; b) K. Liu, C. Resetco, E. Kumacheva, Nanoscale 2012, 4, 6574-6580.

[11] T. J. Cho, R. A. Zangmeister, R. I. MacCuspie, A. K. Patri, V. A. Hackley, Chem. Mater. 2011, 23, 2665-2676.

[12] A. M. E. Badawy, T. P. Luxton, R. G. Silva, K. G. Scheckel, M. T. Suidan, T. M. Tolaymat, Environ. Sci. Technol. 2010, 44, 1260-1266.

[13] a) L. R. Holt, B. J. Plowman, N. P. Young, K. Tschulik, R. G. Compton, Angew. Chem. Int. Ed. 2016, 55, 397-400; b) Y.-G. Zhou, N. V. Rees, J. Pillay, R. Tshikhudo, S. Vilakazi, R. G. Compton, Chem. Commun. 2012, 48, 224-226

[14] a) J. Ellison, C. Batchelor-McAuley, K. Tschulik, R. G. Compton, Sens. Actuators B 2014, 200, 47-52; b) C. Batchelor-McAuley, J. Ellison, K. Tschulik, P. L. Hurst, R. Boldt, R. G. Compton, Analyst 2015, 140 5048-5054.

[15] S. V. Sokolov, E. Kätelhön, R. G. Compton, J. Phys. Chem. C 2015, 119, 25093-25099.

[16] a) Y.-G. Zhou, N. V. Rees, R. G. Compton, Chem. Commun. 2012, 48, 2510-2512; b) N. V. Rees, Y.-G. Zhou, R. G. Compton, Chem. Phys. Lett. 2012, 525-526, 69-71.

[17] P. Waske, T. Wächter, A. Terfort, M. Zharnikov, J. Phys. Chem. C 2014 118, 26049-26060.

[18] S. V. Sokolov, C. Batchelor-McAuley, K. Tschulik, S. Fletcher, R. G. Compton, Chem. Eur. J. 2015, 21, 10741-10746. 


\section{Entry for the Table of Contents}

Layout 1:

\section{COMMUNICATION}

Shaping up: We demonstrate the electrochemical determination of the aspect ratio of gold nanorods on an individual basis through nanoimpact experiments. The measured dimensions are in excellent agreement with electron microscopy results, establishing the use of nanoparticle impact electrochemistry for the characterisation of anisotropic nanomaterials.

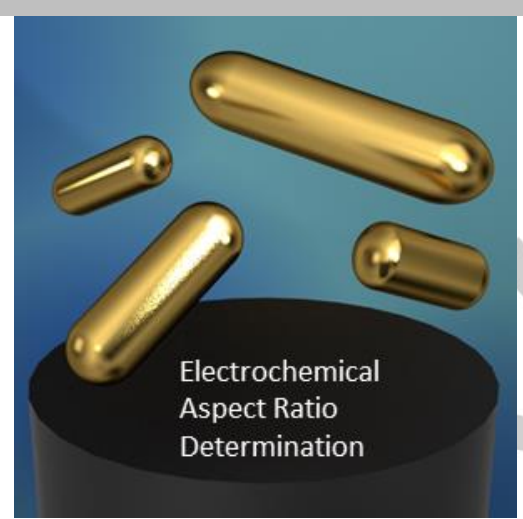

Blake J. Plowman, Neil P. Young, Christopher Batchelor-McAuley and Richard G. Compton*

Page No. - Page No.

Nanorod Aspect Ratios via Nanoimpacts 